\title{
ANÁLISE DO PROGRAMA NACIONAL DE ALIMENTAÇÃO ESCOLAR E OS PROBLEMAS PARA A AQUISIC̣ÃO DE PRODUTOS DA AGRICULTURA FAMILIAR NO RIO GRANDE DO SUL
}

\author{
ANALYSIS OF THE NATIONAL SCHOOL FOOD PROGRAM AND THE \\ PROBLEMS FOR PURCHASING FAMILY FARMING PRODUCTS IN RIO \\ GRANDE DO SUL
}

\author{
José Tobias Marks Machado ${ }^{1}$ \\ Gabriela Rodrigues Bratkowski ${ }^{2}$ \\ Luciana Dias de Oliveira ${ }^{3}$ \\ Etho Roberio Medeiros Nascimento ${ }^{4}$ \\ Vanuska Lima da Silva ${ }^{5}$
}

\begin{abstract}
Resumo
O objetivo deste estudo foi caracterizar e analisar os entraves de operacionalização da compra da agricultura familiar para o Programa Nacional de Alimentação Escolar (PNAE) em municípios com percentual de aquisição inferior a $30 \%$ no estado do Rio Grande do Sul. Foram analisados 28 municípios gaúchos de quatro regiões do estado: Sul, Médio Alto Uruguai, Alto da Serra do Botucaraí e Missões. Foram elaborados e enviados três questionários estruturados com perguntas fechadas e de múltipla escolha, sendo um direcionado aos gestores, um voltado aos técnicos do escritório municipal da Empresa de Assistência Técnica e Extensão Rural, e outro para o nutricionista responsável pela alimentação escolar. Além disso, foi realizada uma análise dos editais de chamada pública de cada município estudado. Dentre os principais resultados destacam-se a falta de profissionais compondo quadro técnico no setor de alimentação escolar e o desconhecimento por parte dos municípios de pontos fundamentais da legislação que rege a compra da agricultura familiar para o PNAE (Lei 11.947/2009). Concluiu-se que apesar dos avanços do PNAE ao longo dos anos em termos legais, sua operacionalização no nível das Entidades Executoras ainda precisa de aperfeiçoamentos.
\end{abstract}

\footnotetext{
${ }^{1}$ Doutorando em Desenvolvimento Rural pela Universidade Federal do Rio Grande do Sul, Porto Alegre - RS, Brasil. E-mail: tobias.machado@hotmail.com

2 Mestre em Saúde Coletiva pela Universidade do Vale do Rio dos Sinos, São Leopoldo - RS, Brasil. E-mail: gabriela.brat@gmail.com

${ }^{3}$ Doutora em Saúde da Criança e do Adolescente (UFRGS). Professora da Universidade Federal do Rio Grande do Sul, Porto Alegre - RS, Brasil.E-mail: dialu73@hotmail.com

${ }^{4}$ Doutorando em Desenvolvimento Rural pela Universidade Federal do Rio Grande do Sul, Porto Alegre - RS, Brasil. E-mail: ethoroberio@gmail.com

${ }^{5}$ Doutora em Ciências dos Alimentos (USP). Professora da Universidade Federal do Rio Grande do Sul, Porto Alegre - RS, Brasil. E-mail: vanuskal@yahoo.com.br
} 
Palavras-chave: Alimentação escolar. Política pública. Responsabilidade técnica. Agricultura familiar.

\begin{abstract}
The objective of this study was to characterize and analyze the operationalization obstacles of the purchase from Family Farming to the National School Food Program (PNAE). It was analyzed 28 municipalities, with an acquisition percentage of less than $30 \%$, from four regions of the state. Three questionnaires structured with closed questions and multiple-choice were elaborated and sent, one to the managers, one to EMATER technicians, and another one to the municipality's nutritionists. Also, a public call notices analysis of each municipality studied was performed. The results point to the lack of nutrition professionals as well as lack of knowledge on the part of municipalities regarding the governing legislation for the purchase from family farming for the PNAE (Law 11.947/2009). It was concluded that, despite the PNAE advances over the years, its operationalization at the level of the Executing Entities still needs improvements.
\end{abstract}

Keywords: School feeding. Public policy. Technical responsibility. Family farming.

\title{
Introdução
}

O Programa Nacional de Alimentação Escolar (PNAE) é amplamente apontado como um marco para as políticas públicas alimentares no Brasil (GRISA; SCHNEIDER, 2015), podendo ser destacados ao menos três aspectos que confirmam tal importância. $\mathrm{O}$ primeiro, relaciona-se a sua longa e ininterrupta história, uma vez que o programa foi criado na metade dos anos 1950, tendo atualmente mais de seis décadas de existência. Em segundo lugar, a abrangência de público caracteriza o PNAE como um programa de acesso universal, atingindo o alunado da rede pública de ensino nos 5.570 municípios do Brasil (TRICHES; SILVESTRI, 2018). Em seguida, os objetivos do PNAE têm uma alta intersetorialidade e complementariedade, ao articular de forma conjunta questões relacionadas à soberania e à segurança alimentar e nutricional (SAN), desenvolvimento regional, dinamização da produção agrícola, agricultura familiar e educação alimentar e nutricional (EAN) (FORNAZIER; BELIK, 2015; TRICHES, 2015). Por fim, os progressos e aperfeiçoamentos realizados ao longo da história do PNAE conferem dinamismo e adequação à realidade brasileira (TRICHES, 2015; VILLAR et al., 2013). Por estas e outras características, Franck et al. (2016) apontam o Programa como uma das políticas públicas mais abrangentes no Brasil.

Em relação aos aperfeiçoamentos, em 1994, o PNAE teve sua primeira modificação, que alterou o modo de execução da política pública, que, na época, se encontrava centralizada na esfera federal do governo e passou a ter a execução descentralizada, nos municípios da federação, chamados a partir deste momento de Entidade Executora (EEx) da política pública. De acordo com Triches (2015) e Franck et al. (2016), embora essa modificação tenha minimizado algumas distorções, como cartelização dos fornecedores, altos custos de distribuição dos alimentos para todo território e a desconsideração da diversidade alimentar regional, ainda não existiam, naquele momento, mecanismos explícitos no Programa que apoiassem o desenvolvimento regional, a agricultura familiar e uma alimentação escolar saudável.

Foi a partir da alteração em 2009, pela instituição da Lei 11.947, que se incrementaram e se notabilizaram novas virtudes do PNAE. Dentre outras questões, o artigo 14 da referida lei estabeleceu que, no mínimo, 30\% dos recursos do Fundo Nacional de Desenvolvimento da Educação (FNDE), destinados à alimentação escolar, deveriam ser aplicados na compra de gêneros alimentícios provenientes da agricultura familiar, sendo assegurada a prioridade para agricultores familiares locais, assentados da reforma agrária, comunidades tradicionais, produtores orgânicos ou agroecológicos e grupos formais de agricultores (BRASIL, 2009).

Segundo Maluf (2009), a partir desse momento, o PNAE tanto criou um elo institucional entre alimentação escolar e agricultura familiar, como também a alimentação oferecida nas escolas passou 
a ser uma potente ferramenta na promoção da reconexão entre produção e consumo local. Já Triches (2015) argumenta que, a partir de 2009, o PNAE se propõe a ser um instrumento de Estado, que tanto favorece a aquisição local de gêneros alimentícios, como também se preocupa em oferecer produtos de melhor qualidade nutricional, ambiental e cultural aos escolares, via compra preferencial dos produtos da agricultura familiar. Cabe dar atenção para o fato de que antes das modificações do ano de 2009, a aquisição de gêneros alimentícios era mediada pela Lei de Licitações (Lei 8.666/1993), a qual se pauta pelo princípio da economicidade na administração pública. A partir do vigor da Lei 11.947/2009, a compra dos produtos da agricultura familiar poderia ser realizada via chamada pública, a qual objetiva pagar o preço médio do mercado local aos ofertantes do Programa, sem haver disputa de preços ou concorrência entre os fornecedores.

Diversos trabalhos têm apontado a importância do PNAE para a promoção do desenvolvimento local, acesso aos mercados pelos agricultores familiares, bem como suas potencialidades no que diz respeito ao aumento da disponibilidade de alimentos de qualidade nutricional superior, e adequados à cultura alimentar regional (ESTEVAM; SALVARO; SANTOS, 2018; SOUSA et al., 2018; TRICHES, 2014). Além disso, na esteira da experiência brasileira com o PNAE, diversos países, como Estados Unidos, Paraguai, Japão, Tailândia, Itália, Escócia, Gana e Nigéria, têm desenvolvido iniciativas similares que objetivam aproximar a produção e o consumo de alimentos no âmbito escolar, via compra de produtos de agricultores locais (SWENSSON, 2018; TRICHES; SILVESTRI, 2018).

Embora devam ser reconhecidos e destacados os avanços da última modificação do Programa, Triches e Silvestri (2018) argumentam que, dado o aumento da complexidade para sua execução, o modelo adotado a partir de 2009 ainda está em fase de aprimoramentos, sendo que novos e antigos desafios se impõem para a melhor operacionalização dessa política pública (BRATKOWSKI et al., 2018; ESTEVAM; SALVARO; SANTOS, 2018; SILVA; ROCHETT; COELHO DE SOUZA, 2018). Tratando-se especificamente da compra de produtos da agricultura familiar, se, por um lado, muitos trabalhos apontam o aumento da demanda pelas entidades executoras em estados como Tocantins (SOUSA et al., 2018), Paraná, Rio Grande do Sul, Santa Catarina, Espírito Santo e Roraima (FRANCK et al., 2016; TRICHES; SILVESTRI, 2018), por outro, Triches e Silvestri (2018) descrevem, por exemplo, falhas nos editais de chamada pública de prefeituras do Paraná, o que segundo as autoras dificulta a correta operacionalização do Programa.

Especificamente para o estado do Rio Grande do Sul, os dados do FNDE demonstram que, desde a promulgação da lei, nota-se um gradativo aumento do investimento nas compras da agricultura familiar, o qual atingiu um montante máximo de 48,8 milhões de reais em 2015, tendo uma queda para 43,5 milhões em $2016^{6}$ (FNDE, 2018). Em relação aos municípios que não estão em conformidade com a legislação - com compra inferior aos $30 \%$ do recurso recebido do FNDE - em 2011, 10\% dos $496^{7}$ municípios gaúchos não apresentavam investimento algum na compra da agricultura familiar, enquanto outros 38\% tinham investimentos inferiores ao valor mínimo de $30 \%$. Nos últimos cinco anos, observa-se uma queda vertiginosa no número de municípios que não fizeram compra alguma, sendo que, em 2016, apenas onze municípios do estado (2\%) não compravam produtos da agricultura familiar. Por outro lado, de 2011 a 2016, nota-se uma estabilidade no percentual de municípios que, embora comprem da agricultura familiar, não atingem o percentual mínimo estabelecido pela Lei 11.947/2009. Assim, enquanto em 2011 cerca de 38\% dos municípios gaúchos estavam em desacordo com a legislação do PNAE, esse percentual caiu para 33\%, em 2016, havendo uma baixa variação no número de municípios em desacordo com a legislação vigente.

Diante dessa situação, este trabalho tem como objetivo caracterizar e analisar os entraves de operacionalização da compra da agricultura familiar para atendimento do PNAE em municípios com percentual de aquisição inferior a $30 \%$ no estado do Rio Grande do Sul. Para tanto, além desta primeira seção, o trabalho será dividido em mais quatro partes. Em seguida, serão apresentados os procedimentos metodológicos que embasaram a seleção dos municípios analisados, bem como as ferramentas analíticas utilizadas para caracterização das dificuldades. A terceira seção traz uma apresentação das regiões dos municípios previamente selecionados, para que, na seção subsequente, sejam apresentados os principais resultados obtidos. Por fim, são tecidas as considerações finais.

\footnotetext{
${ }^{6} \mathrm{Em} 2016$, foram investidos $\mathrm{R} \$ 44$ milhões na compra da agricultura familiar, cifra próxima aos R $\$ 43,6$ milhões investidos em 2014 (FNDE, 2018).

${ }^{7}$ Desde 2013, o estado conta com 497 municípios.
} 


\section{Procedimentos metodológicos}

O presente estudo tem caráter quantitativo e descritivo, o qual utilizou dados de uma ação intitulada "Oficinas regionais para o levantamento da demanda da alimentação escolar e da produção da agricultura familiar para a boa execução do PNAE". As oficinas regionais, realizadas no ano de 2018, fizeram parte do projeto de extensão do Centro Colaborador em Alimentação e Nutrição do Escolar da Universidade Federal do Rio Grande do Sul (CECANE UFRGS).

Fizeram parte do estudo 28 municípios do estado do Rio Grande do Sul, selecionados a partir dos seguintes critérios: 1) municípios que não alcançaram a compra da agricultura familiar de pelo menos 30\% nos anos 2014, 2015 e 2016; 2) municípios que não alcançaram a compra de pelo menos $30 \%$ em 2016 e 2015 ou 2014; 3) municípios que não alcançaram a compra de pelo menos 30\% em 2016; 4) municípios que não alcançaram a compra de pelo menos 30\% em 2015 ou 2014. Os dados sobre o percentual de aquisição dos produtos da agricultura familiar foram extraídos da prestação de contas dos municípios, a qual foi analisada e divulgada no site do FNDE (FNDE, 2018). Com base nos critérios descritos acima, para atingir o objetivo de diagnosticar as dificuldades enfrentadas pelas Entidades Executoras do PNAE, foram selecionados municípios de quatro regiões do estado, garantido assim uma representatividade regional das situações. Nesse sentido, fez-se a seleção de sete municípios da Região $\mathrm{Sul}^{8}$, seis municípios do Médio Alto Uruguai ${ }^{9}$, sete municípios da Região Alto da Serra do Botucaraí ${ }^{10}$, e outros oito municípios da Região Missões ${ }^{11}$, totalizando 28 municípios. Na figura 1, é apresentada a localização dos municípios classificados nas quatro regiões.

Figura 1: Regióes que tiveram municípios selecionados

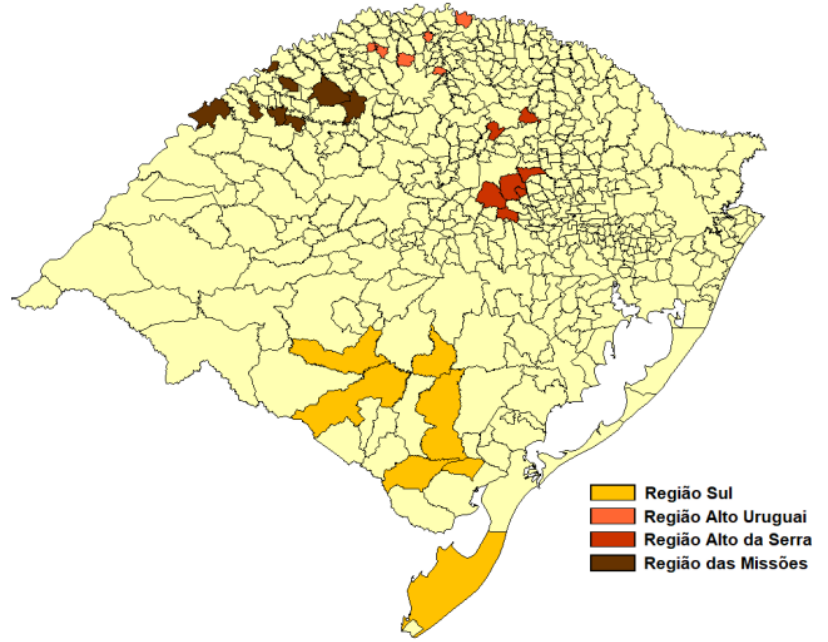

Fonte: Elaborado pelos autores via TabWin (2018).

Para a coleta de dados, foram elaborados, no Google Forms ${ }^{\circledR}$, três questionários estruturados com perguntas fechadas e de múltipla escolha, sendo um direcionado aos gestores (Secretário/a da Educação), um voltado aos técnicos do escritório municipal da Empresa de Assistência Técnica e Extensão Rural (EMATER), e outro para o nutricionista responsável pela alimentação escolar. Os links para acesso e preenchimento dos questionários foram enviados por correio eletrônico, entre os meses de abril e junho, sendo contemplados quatro eixos temáticos de perguntas. As questões encaminhadas aos respectivos respondentes são sintetizadas no quadro 1.

\footnotetext{
${ }^{8}$ Piratini, Herval, Pedro Osório, Santana da Boa Vista, Lavras do Sul, Santa Vitória do Palmar e Bagé.

${ }^{9}$ Bom Progresso, Braga, Cristal do Sul, Dois Irmãos das Missões, Rio dos Índios, São José das Missões.

${ }^{10}$ Arvorezinha, Barros Cassal, Boqueirão do Leão, Ernestina, Fontoura Xavier, Mato Castelhano, São José do Herval.

${ }^{11}$ Caibaté, Cândido Godói, Catuípe, Dezesseis de Novembro, Garruchos, Giruá, Porto Vera Cruz, Rolador.
} 
Quadro 1: Perguntas encaminhadas aos gestores, nutricionistas e representantes da Emater local, classificadas nos quatro eixos temáticos

\begin{tabular}{|c|c|c|}
\hline Eixo Temático & Pergunta do questionário & Respondentes \\
\hline \multirow{3}{*}{$\begin{array}{l}\text { (I) execução do } \\
\text { PNAE }\end{array}$} & 1. Há nutricionista que assume a responsabilidade técnica do PNAE? & \multirow[b]{2}{*}{ Nutricionista } \\
\hline & $\begin{array}{l}\text { 2. Quantos nutricionistas são lotados no setor de alimentação } \\
\text { escolar, compondo o Quadro Técnico (QT)? }\end{array}$ & \\
\hline & $\begin{array}{l}\text { 3. O município complementa com recurso próprio os recursos } \\
\text { provindos do FNDE destinados à alimentação escolar? }\end{array}$ & Gestor \\
\hline \multirow{11}{*}{$\begin{array}{l}\text { (II) Compra da } \\
\text { Agricultura } \\
\text { Familiar }\end{array}$} & $\begin{array}{l}\text { 4. No processo de elaboração dos cardápios, o nutricionista teve } \\
\text { acesso ao mapeamento agrícola local? }\end{array}$ & \multirow{5}{*}{ Nutricionista } \\
\hline & $\begin{array}{l}\text { 5. Já ocorreu o caso de não haver proposta (projeto de venda) para } \\
\text { determinado(s) produto(s) que contemplava a lista de compras? }\end{array}$ & \\
\hline & $\begin{array}{l}\text { 6. O nutricionista acompanha o processo de compras dos produtos } \\
\text { da agricultura familiar (Edital de Chamada Pública ou licitação)? }\end{array}$ & \\
\hline & $\begin{array}{l}\text { 7. Ocorrem no município reuniões de articulação entre a EEx com os } \\
\text { agricultores familiares locais para tratar sobre a compra destes } \\
\text { gêneros? }\end{array}$ & \\
\hline & 7.1 Caso sim, qual a periodicidade destas reuniões? & \\
\hline & $\begin{array}{l}\text { 8. Qual o percentual de compra da agricultura familiar atingido no } \\
\text { último ano? }\end{array}$ & \multirow{3}{*}{ Gestor } \\
\hline & $\begin{array}{l}\text { 9. O município tem conhecimento sobre a Resolução do FNDE no } 04 \\
\text { de } 02 \text { de abril de } 2015 \text { e a segue nos editais de aquisição dos } \\
\text { alimentos? }\end{array}$ & \\
\hline & $\begin{array}{l}\text { 10. Selecione nas opções abaixo a forma de definição dos preços } \\
\text { dos gêneros da agricultura familiar a serem adquiridos: }\end{array}$ & \\
\hline & $\begin{array}{l}\text { 11. O município possui Serviço de Inspeção Municipal (SIM) ou } \\
\text { Serviço de Inspeção Estadual (SIE)? }\end{array}$ & \multirow{3}{*}{ EMATER } \\
\hline & 12. A Emater tinha conhecimento do percentual de compra do PNAE & \\
\hline & $\begin{array}{l}\text { 13. A Entidade Executora (EEx) faz contato com a Emater para } \\
\text { operacionalização e viabilização da compra da agricultura familiar? }\end{array}$ & \\
\hline \multirow{9}{*}{$\begin{array}{l}\text { (III) Dificuldade } \\
\text { de } \\
\text { operacionalização }\end{array}$} & $\begin{array}{l}\text { 14. Há impossibilidade de emissão do documento fiscal pelos } \\
\text { Agricultores Familiares? }\end{array}$ & \multirow{7}{*}{ Nutricionista } \\
\hline & $\begin{array}{l}\text { 15. Há inviabilidade de fornecimento regular e constante dos gêneros } \\
\text { alimentícios, respeitando a sazonalidade dos produtos, por parte dos } \\
\text { Agricultores Familiares? }\end{array}$ & \\
\hline & $\begin{array}{l}\text { 16. As condições higiênico-sanitárias dos produtos são inadequadas, } \\
\text { isto é, que estejam em desacordo com o disposto no art. } 33 \text { da } \\
\text { Resolução CD/FNDE n²6/2013? }\end{array}$ & \\
\hline & 17. Há dificuldade para se efetuar a pesquisa de preço? & \\
\hline & 18. Há dificuldade para a elaboração do edital Chamada pública? & \\
\hline & 19. Há dificuldade para habilitação e seleção dos projetos de venda? & \\
\hline & 20. Há dificuldade para o estabelecimento do contrato de compra? & \\
\hline & $\begin{array}{l}\text { 21. Há dificuldade para elaboração do projeto de venda pelos } \\
\text { agricultores? }\end{array}$ & \multirow{2}{*}{ Emater } \\
\hline & $\begin{array}{l}\text { 22. Há dificuldades de se encontrar agricultores interessados em } \\
\text { vender ao PNAE? }\end{array}$ & \\
\hline \multirow{4}{*}{ (IV) Opinião } & $\begin{array}{l}\text { 23. Em sua opinião, qual a importância da Agricultura Familiar no } \\
\text { desenvolvimento do seu município? }\end{array}$ & \multirow{4}{*}{ Todos } \\
\hline & $\begin{array}{l}\text { 24. Em sua opinião, qual é a importância do PNAE para o } \\
\text { fortalecimento e desenvolvimento da Agricultura Familiar no seu } \\
\text { município? }\end{array}$ & \\
\hline & $\begin{array}{l}\text { 25. Em sua opinião, qual o grau de interesse dos agricultores do seu } \\
\text { município em vender para a alimentação escolar? }\end{array}$ & \\
\hline & $\begin{array}{l}\text { 26. Em sua opinião, qual o percentual de compra de gêneros para a } \\
\text { alimentação escolar, oriundos da agricultura familiar, que seu } \\
\text { município deveria e/ou teria potencial de atingir? }\end{array}$ & \\
\hline
\end{tabular}


Dos 84 questionários encaminhados, houve retorno de 98,8\%, de modo que apenas um questionário, destinado à Emater, não foi respondido. $O$ não retorno, nesse caso, decorreu de o município não ter escritório municipal da Emater. Além das 27 perguntas que abrangeram os quatro eixos temáticos, fez-se também a análise dos editais de chamada pública para compra da agricultura familiar, os quais foram encaminhados pelas 28 Entidades Executoras. A análise dos editais buscou averiguar a conformidade de tais documentos com a Resolução $\mathrm{n}^{0} 04$, de 02 de abril de 2015, do FNDE, a qual regulamenta o processo de chamada pública para compra da agricultura familiar.

Por fim, cabe destacar que foram levantados dados secundários em plataformas da Fundação de Economia Estatística (FEE) e do Instituto Brasileiro de Geografia e Estatística (IBGE), para caracterização regional. Tais dados disseram respeito à estimativa populacional dos municípios, contribuição da agricultura no Valor Agregado Bruto do município, número de estabelecimentos da agricultura familiar, número de Documentos de Aptidão ao Pronaf (DAPs) e cálculo do índice de diversificação da produção agropecuária (IDPA), este seguindo a metodologia proposta por Waquil e Filippi $(2008)^{12}$.

\section{Caracterização regional: compra da agricultura familiar, aspectos demográficos e produtivos}

Esta seção busca caracterizar as quatro regiões a partir do uso de dados secundários dos municípios selecionados. Assim, cabe inicialmente ser apresentado o desempenho das Entidades Executoras na compra dos produtos da agricultura familiar. Embora, neste estudo, a escolha dos municípios privilegiou a quantidade de compra efetuada nos anos 2014, 2015 e 2016, a figura 2 concatena a média de investimentos em compra de produtos da agricultura familiar entre os anos 2011e 2017. Com base nisso, pode-se analisar que o valor médio permaneceu abaixo de $30 \%$ na maior parte dos anos em todas as regióes, demonstrando dificuldades crônicas em ser efetuada compra da agricultura familiar na maior parte dos municípios selecionados. Como pode também ser visto na figura 2, a compra média para o ano de 2017 teve uma melhora significativa na região Alto da Serra do Botucaraí, no entanto deve ser ponderado que os dados relativos a esse ano, em específico, são ainda preliminares e por isso passíveis de modificação até a divulgação oficial pelo FNDE.

Figura 2: Média da compra da agricultura familiar pelos municípios selecionados, classificados por região

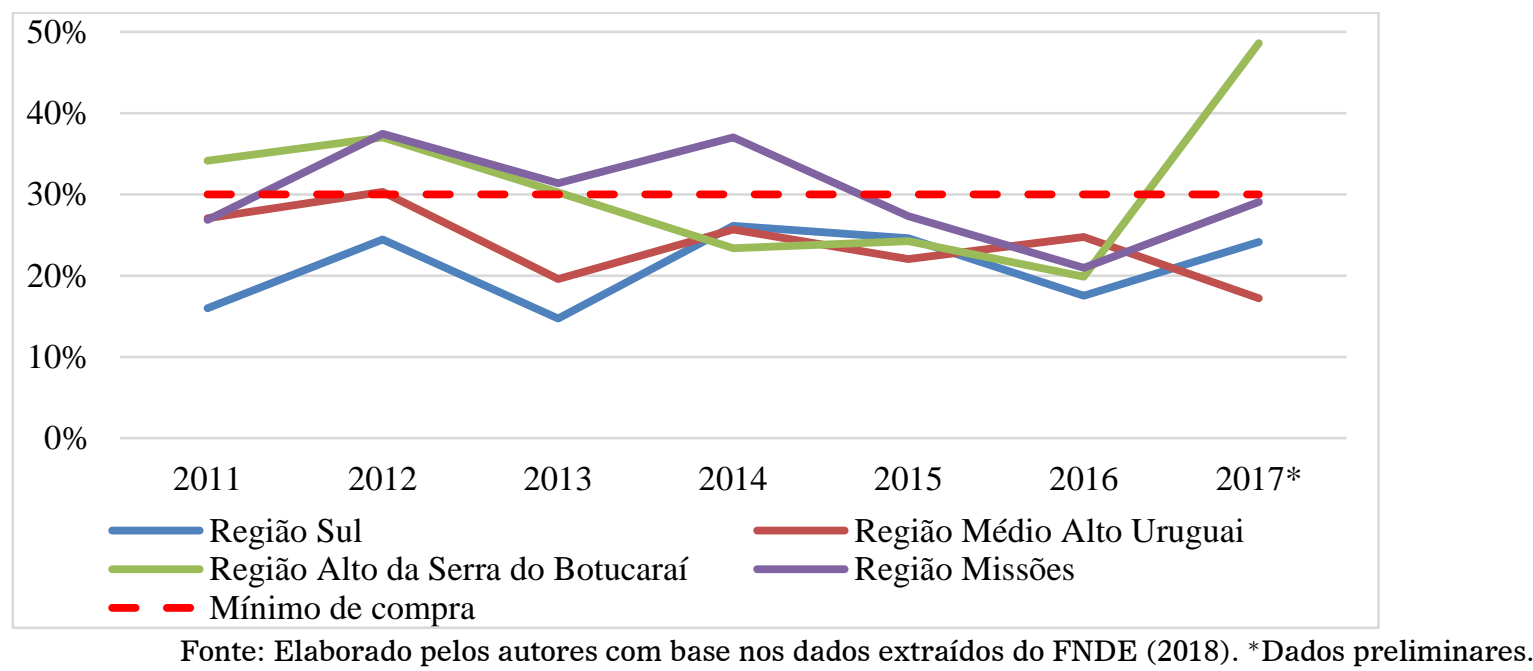

Levando em consideração os dados oficiais dos três últimos anos, nota-se que a região Sul é a que reúne o maior número de municípios com dificuldades de compras da agricultura familiar, sendo que dos sete municípios aqui analisados, cinco se enquadraram no critério 1 de seleção - tendo compra inferior a 30\% de 2014 até 2016. Já os outros dois municípios dessa região, tiveram

\footnotetext{
$12 \mathrm{O}$ cálculo seguiu a seguinte equação: $\mathbf{I D P A}=\mathbf{1}-\mathbf{\Sigma} \mathbf{n i}=\mathbf{1} \mathbf{S i}^{2}$

Para este estudo, tomou-se a participação (Si) de 37 produtos de origem vegetal e 5 produtos de origem animal, medidos em toneladas. $\mathrm{O}$ somatório das participações ao quadrado corresponde ao índice de concentração da produção e pode assumir o valor máximo de 1, representando assim o caso extremo em que apenas uma atividade é existente. De modo oposto, o índice de diversificação é entendido como o complemento ao índice de concentração, sendo que, quanto maior for o índice de concentração, menor será o índice de diversificação e vice-versa.
} 
enquadramento do critério 2 - com compra inferior ao estipulado em lei nos anos 2016 e 2014 ou 2015. Na região Médio Alto Uruguai, por sua vez, quatro dos seis municípios se enquadraram no critério 1, enquanto as Regiões Alto da Serra do Botucaraí e Missões tiveram três municípios selecionados por este primeiro critério. Como pode ser observado na tabela 1, dos 28 municípios 54\% foram selecionados pelo primeiro critério, enquanto outros $21 \%$ se enquadraram no critério 2 , demonstrando assim que os problemas de compra da agricultura familiar, na maior parte dos municípios estudados, não se restringem a problemas momentâneos e restritos a um único ano.

Tabela 1: Número e percentual de municípios conforme critério de seleção e região de origem

\begin{tabular}{|c|c|c|c|c|c|}
\hline \multirow[b]{2}{*}{ Critério } & \multicolumn{4}{|l|}{ Região } & \multirow{2}{*}{$\begin{array}{l}\text { Percentual } \\
\text { de } \\
\text { municípios }\end{array}$} \\
\hline & $\begin{array}{l}\text { Região } \\
\text { Sul }\end{array}$ & $\begin{array}{l}\text { Região Médio Alto } \\
\text { Uruguai }\end{array}$ & $\begin{array}{l}\text { Região Alto da Serra do } \\
\text { Botucaraí }\end{array}$ & $\begin{array}{l}\text { Região } \\
\text { Missões }\end{array}$ & \\
\hline Critério 1 & 5 & 4 & 3 & 3 & $53,57 \%$ \\
\hline Critério 2 & 2 & 0 & 2 & 2 & $21,43 \%$ \\
\hline Critério 3 & 0 & 0 & 1 & 3 & $14,29 \%$ \\
\hline Critério 4 & 0 & 2 & 1 & 0 & $10,71 \%$ \\
\hline
\end{tabular}

Fonte: Elaborado pelos autores com base nos dados de pesquisa (2018).

Dada a diversidade da agricultura no estado do Rio Grande do Sul (MIGUEL, 2018; SILVA NETO; OLIVEIRA, 2008), cabem ser apreciados alguns indicadores demográficos e produtivos das regiões abrangidas pelos municípios selecionadas. Nesse sentido, como é apresentado na tabela 2, excetuando-se a região Sul, grande parte dos municípios têm um amplo contingente populacional residindo no meio rural. Tratando-se de aspectos produtivos, pode ser avaliado que a agricultura é atividade econômica importante, com contribuição mais significativa nos municípios da região Médio Alto Uruguai. Quanto à importância da agricultura familiar, todos os municípios selecionados detêm mais da metade dos estabelecimentos agropecuários classificados como familiares, sendo que as regiões situadas na metade norte do estado são aquelas com predominância de estabelecimentos familiares. No entanto, quando analisada a relação entre o número de Declarações de Aptidão ao Pronaf (DAPs) e estabelecimentos familiares, é a região Sul que se destaca com maior número de DAPs disponíveis. Aqui, cabe ressaltar que a DAP é o documento que habilita os agricultores familiares a vender ao PNAE, sendo fundamental para os interessados em acessar esse mercado institucional.

Tabela 2: Aspectos demográficos e produtivos dos municípios estudados, classificados por região de origem

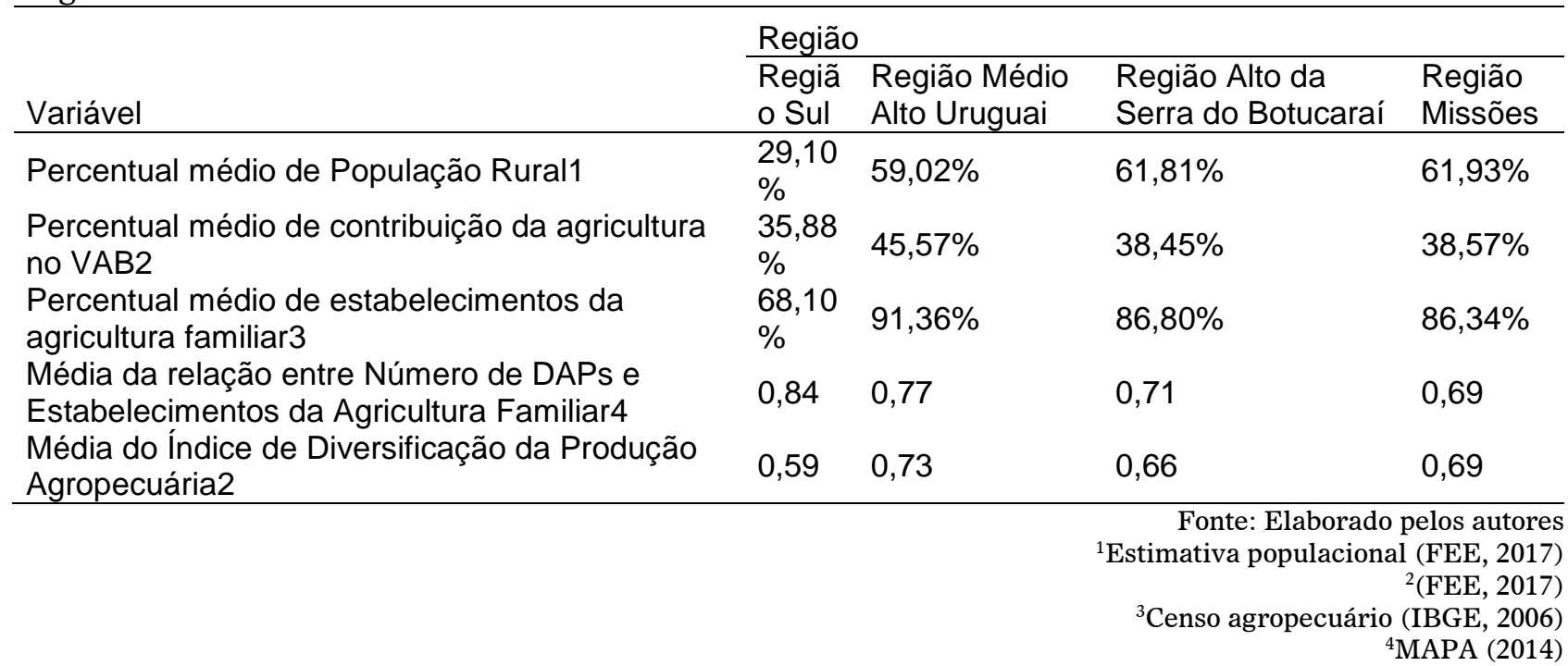

Por fim, tratando-se da diversificação da agricultura, enquanto a região Médio Alto Uruguai tem um maior portfólio de produtos agropecuários, a região Sul se caracteriza por uma concentração da produção em um número menor de produtos, o que tende a impactar na diversidade de itens 
passíveis de serem ofertados ao PNAE. Feita essa caracterização geral das regiões, baseada nos indicadores dos municípios selecionados neste estudo, passamos à análise dos principais dados levantados.

\section{Apresentação dos resultados e discussões}

Esta seção apresenta e discute, por eixo temático, os principais resultados obtidos a partir do envio dos questionários aos nutricionistas, gestores e representantes da Emater municipal. São também discutidos e apresentados os resultados da análise dos editais de chamada pública dos 28 municípios.

Quanto ao "Eixo Temático I", o qual abordou aspectos sobre a execução do PNAE, pode ser constatado que todos os municípios têm ao menos um nutricionista que assume a Responsabilidade Técnica do Programa, tal como previsto pela legislação. No entanto, quando analisada a composição de Quadro Técnico do setor de alimentação escolar, metade dos municípios (14) não atende à Resolução do Conselho Federal de Nutrição (CFN) n 465 de 23 de agosto de 2010 (CFN, 2010), a qual é a referência para cálculo do número de nutricionistas para o PNAE. O maior déficit de profissionais ocorre nos municípios da região Sul, sendo que, em nenhum dos sete municípios, há um número adequado de nutricionistas. Ao contrário disso, todos os seis municípios do Médio Alto Uruguai têm número adequado de trabalhadores. É importante destacar que o déficit de profissionais pode afetar negativamente a compra da agricultura familiar, uma vez um quadro técnico insuficiente tende a dificultar o acompanhamento do nutricionista no processo de compras. Concordando com isso, Bratkowski et al. (2018) destacam que a inadequação do número de nutricionistas para execução do PNAE é um dos problemas mais frequentes nos municípios do Rio Grande do Sul. Ainda se tratando da execução do Programa, segundo os gestores, grande parte dos municípios faz complementação dos recursos advindos do FNDE (26 municípios), com recursos próprios, tal como recomendado pela legislação (BRASIL, 2009).

Sobre a compra da agricultura familiar, a qual caracteriza o Eixo Temático II, a figura 3 apresenta os resultados extraídos dos questionários enviados aos nutricionistas e gestores. A maior parte dos nutricionistas destacou ter acesso ao mapeamento agrícola local, acompanhar o processo de compras da agricultura familiar, e afirma existirem reuniões de articulação entre os representantes da Entidade Executora e os agricultores para tratar da compra de gêneros para a alimentação escolar. Cabe desatacar que tais procedimentos são adequados e recomendados pelo FNDE (2016) para que haja uma boa operacionalização da compra da agricultura familiar, sendo que devem ser realizados antes da abertura do edital de chamada pública, para que justamente sejam evitados problemas de não aderência entre os itens demandados e os produtos localmente produzidos. No entanto, $43 \%$ dos nutricionistas destacaram casos de inexistência de propostas de venda para itens contemplados nos editais de chamada pública, de modo que falhas na articulação e/ou mapeamento dos produtos da agricultura local podem estar ocorrendo. Nesse sentido, um dado complementar sobre o grau de articulação entre os atores reforça esta hipótese, pois, dos 20 municípios que afirmaram realizar as reuniões de articulação, apenas 4 destacaram que estas ocorrem com algum tipo de regularidade. 
Figura 3: Compra da agricultura familiar nos 28 municípios pesquisados

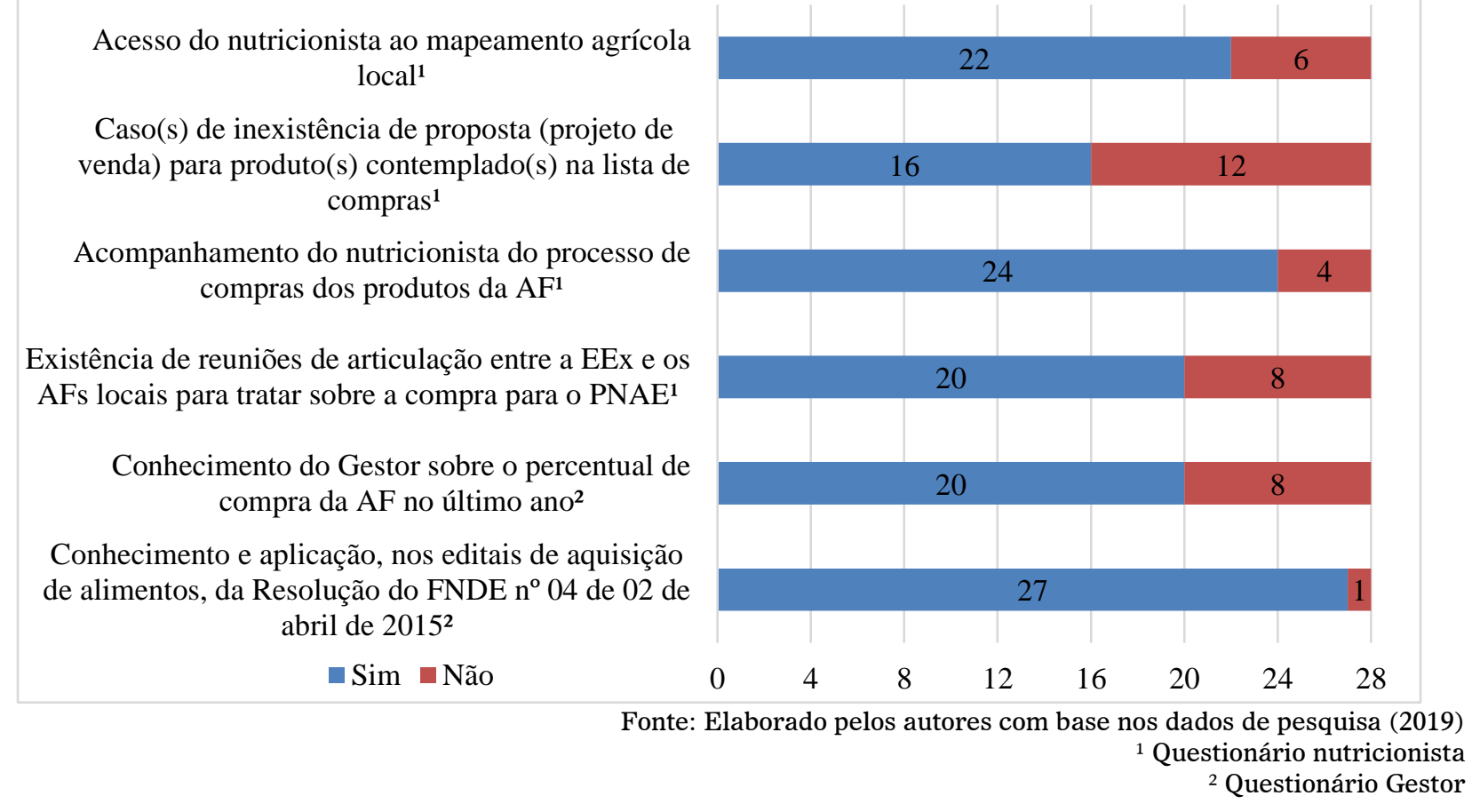

Analisando chamadas públicas e compras da agricultura familiar no Paraná, Triches e Silvestri (2018) demonstram falta de coerência entre a quantidade de alimentos solicitados e a quantidade realmente comprada, indicando que tal falha tende a impactar negativamente na organização dos fornecedores. Já Baccarin et al. (2011), em chamadas públicas no estado de São Paulo, verificaram não correspondência entre alimentos solicitados e aqueles produzidos regionalmente. Com base nisso, pode-se afirmar que a falta de articulação e de conhecimento da produção local, tende a produzir editais de compra com pouca aderência entre gêneros produzidos e requeridos, afetando negativamente a disponibilidade de agricultores interessados no fornecimento dos produtos, além de gerar também desabastecimento de itens e frustração da compra planejada da agricultura familiar.

Em termos regionais, a maior frequência de respostas negativas sobre o acesso ao mapeamento da produção agrícola local ocorreu na região Sul (4 municípios), justamente a região em que $100 \%$ dos municípios pesquisados destacaram casos de inexistência de projetos de venda para gêneros requeridos em edital de chamada pública, deixando explicitada a importância da realização do mapeamento agrícola antes da publicação do edital de compra. Tratando-se dos gestores, em 20 municípios, demonstrou-se conhecimento sobre o percentual de compra da agricultura familiar atestando, de certa forma, conhecimento sobre a operacionalização do PNAE no município. Na mesma linha, a ampla maioria disse conhecer e aplicar a Resolução $\mathrm{n}^{\circ} 4$ de 2015 do FNDE nos editais de chamada pública, porém essa resposta é contrariada pela análise dos editais de chamada pública, como será visto adiante.

Quanto à forma de definição dos preços dos produtos da agricultura familiar, a ser utilizado no edital de chamada pública, nove gestores destacaram consultar preços em feiras ou cooperativas de agricultores familiares, 11 afirmaram utilizar tanto feiras de agricultores como também mercados convencionais. Já em sete municípios, a consulta de preços é realizada apenas em mercados convencionais, sendo que um gestor afirmou utilizar o menor preço de mercado disponível. A análise desses resultados permite inferir que apenas os nove primeiros municípios seguem a recomendação da Resolução ${ }^{\circ}$ 04/2015, do FNDE, a qual informa que a formação do preço médio de aquisição deve priorizar os mercados da agricultura familiar (BRASIL, 2015; FNDE, 2016). Embora os municípios que, de algum modo, utilizam os mercados convencionais para consulta de preços não estejam em desacordo com a legislação, o uso de preços de mercados convencionais tende a causar menor interesse dos agricultores em participar do Programa, descaracterizando também algumas das virtudes do PNAE, como aquela relacionada à valorização da produção local (BARBOSA et al., 2018; MALINA, 2012). Cabe destacar, por último, que o município que afirmou fazer uso do menor preço descaracterizou o processo de compra por chamada pública. 
Tratando-se das respostas dos representantes da Emater, sobre a compra da agricultura familiar, dos 27 municípios que têm escritório da empresa de assistência técnica, nove informaram não contar com nenhum serviço de inspeção sanitária. Como argumentado por Triches e Schneider(2010), uma das dificuldades enfrentadas pelo Programa Nacional de Alimentação Escolar relaciona-se com as exigências sanitárias e de qualidade, de modo que aqueles municípios que não têm algum tipo de serviço de inspeção municipal (SIM) acabam por inviabilizar o fornecimento de gêneros agroindustrializados produzidos pela agricultura local. Regionalmente, enquanto no Médio Alto Uruguai apenas dois municípios dispõem de serviço de inspeção, nas Missões apenas um município não tem esse tipo de serviço. Quando questionado se a Emater participa das articulações para compra da agricultura familiar, a maior parte dos extensionistas (24) respondeu positivamente a essa questão, porém 19 profissionais da Emater foram os que informaram corretamente a quantidade de aquisição da agricultura familiar realizada pela Entidade Executora no último ano. As dificuldades de operacionalização do PNAE, que abrangem o terceiro Eixo Temático, são apresentadas na figura 4. De acordo com os nutricionistas, uma das principais dificuldades diz respeito à inviabilidade de fornecimento regular e constante dos gêneros, por parte dos agricultores familiares. Este problema se concentra nas regióes Sul e Alto da Serra do Botucaraí, com quatro e três casos, respectivamente, de não atendimento da demanda de alimentos. Em Tocantins, quando consultados os agricultores, estes destacaram que um dos entraves para a operacionalização do PNAE se relacionava à dinâmica de fornecimento dos gêneros (BARBOSA et al., 2018). Nesse sentido, cabe destacar que, para o melhor funcionamento da logística de fornecimento, a Resolução $n^{\circ} 26 / 2013$, no seu artigo 29, passou a indicar que as despesas com entregas, logística e embalagens devem ser previstas no momento da definição dos preços para aquisição da agricultura familiar (BRASIL, 2013), de modo que uma definição de preços inadequada pode criar obstáculos para o fornecimento dos gêneros, ou até mesmo interromper esse processo. Corroborando esse fato, a pesquisa de preços foi tratada como um entrave em cinco municípios, principalmente localizados na região sul. Positivamente, por sua vez, casos de condições higiênico-sanitárias inadequadas dos alimentos e dificuldade de habilitação dos projetos de venda, foram pouco apontadas pelos nutricionistas. Quanto às respostas fornecidas pela Emater, chama a atenção as dificuldades relativas à existência de agricultores interessados em comercializar para o PNAE. Diferentemente de outros problemas diagnosticados, não há uma concentração regional dessa dificuldade, sendo que em todas as regiões ao menos dois municípios destacaram esse tipo de contrariedade.

Figura 4: Dificuldades de operacionalização do PNAE

Impossibilidade de emissão de documento fiscal pelos $\mathrm{AF}^{\mathbf{1}}$

Inviabilidade de fornecimento regular e constante dos gêneros alimentícios ${ }^{1}$

As condições higiênico-sanitárias dos produtos são inadequadas $^{1}$

Dificuldade para se efetuar a pesquisa de preço $^{1}$

Dificuldade para a elaboração do edital de chamada pública $^{1}$

Dificuldade para habilitação e seleção dos projetos de venda ${ }^{1}$

Dificuldade para o estabelecimento do contrato de compra ${ }^{1}$

Dificuldade para elaboração do projeto de venda pelos agricultores ${ }^{3}$

Dificuldade em se encontrar agricultores interessados em vender para o $\mathrm{PNAE}^{3}$

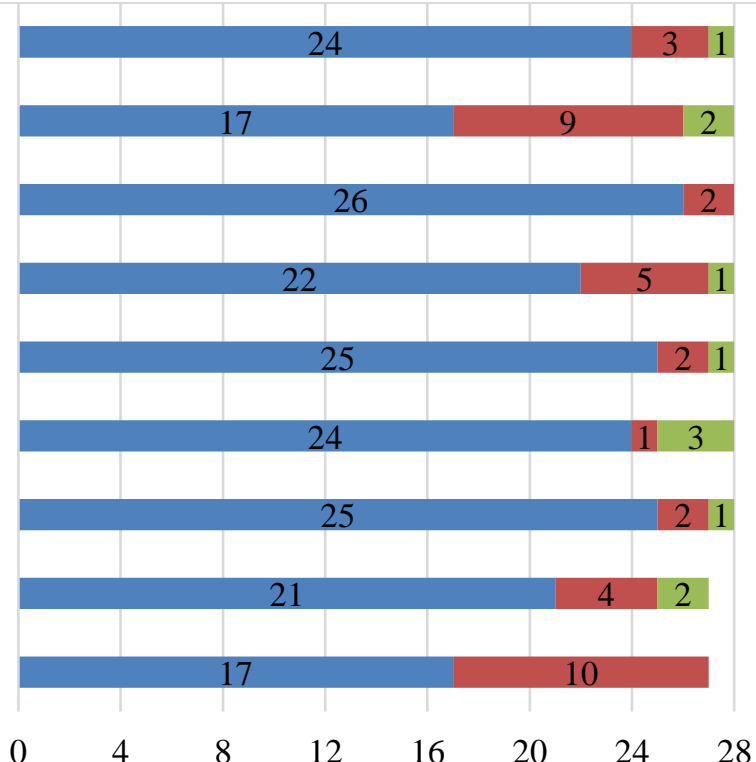

$\begin{array}{lllllllllll} & \text { Não } & \text { Sim Não sabe informar } & 0 & 4 & 8 & 12 & 16 & 20 & 24 & 28\end{array}$

Fonte: Elaborado pelos autores com base nos dados de pesquisa (2019)

${ }^{1}$ Questionário nutricionista

${ }^{3}$ Questionário Emater

Levando-se em consideração que a compra da agricultura familiar deve ser preferencialmente regida por edital de chamada pública, sendo que erros no mesmo tendem a causar prejuízos na compra da agricultura familiar (TRICHES; SILVESTRI, 2018), é interessante 
analisarmos os resultados sobre a adequação dos editais das 28 Entidades Executoras em conformidade à Resolução $n^{\circ}$ 04, de 02 de abril de 2015, do FNDE. Atentando aos principais pontos da referida resolução, a análise do questionário utilizou 16 questões que buscaram atestar a conformidade ou não dos documentos. Como pode ser visualizado na figura 5 , o primeiro ponto de averiguação contradiz grande parte das respostas fornecidas pelos gestores sobre uso e aplicação da Resolução 04/2015 nos editais, uma vez que apenas nove documentos citavam nominalmente serem regidos pelas resoluções e lei do PNAE. Embora com menor frequência, quatro municípios tinham erros graves em seus editais, uma vez que não apresentavam a data de abertura do edital nem mesmo a data máxima de entrega das propostas pelos agricultores. Geograficamente, tais erros se distribuíram em um município de cada região analisada. Um ponto contemplado por todos os editais teve relação com a descrição adequada do objeto da chamada pública, ou seja, todas as EEx destacaram que a chamada pública serviria apenas para compra de alimentos ao PNAE.

Já a descrição do local de entrega dos gêneros foi um ponto errático na maior parte das chamadas públicas, uma vez que 15 editais não informaram onde e com qual periodicidade os alimentos fornecidos pelos agricultores familiares deveriam ser entregues. A inexistência dessa informação tende a ser um fator prejudicial para a execução da compra da agricultura familiar, pois, de acordo com Guilhoto et al. (2006), a logística de distribuição da produção agropecuária não é simples e, por isso, requer procedimentos com alto nível de organização para evitar o fracasso da atividade. Na mesma linha, Baccarin et al. (2011) destacam que a adequação e a adesão dos agricultores ao mercado institucional requerem a presença de chamadas públicas com a apresentação de cronogramas que descrevam a periodicidade e o local de entrega, para que, assim, o agricultor esteja ciente de sua possibilidade de distribuição dos gêneros antes da habilitação do seu projeto de venda, permitindo aos produtores tempo de planejamento de suas atividades (TRICHES; SILVESTRI, 2018). Ao analisar chamadas públicas em municípios do Paraná, as mesmas autoras verificaram um alto percentual de chamadas públicas que não informavam o local e a periodicidade de entrega (93\%). Contudo, em pesquisa realizada em São Paulo, Baccarin et al. (2011) constataram que apenas $16,6 \%$ das chamadas analisadas não definiam a periodicidade das entregas. Cabe destacar que $100 \%$ dos municípios do Alto da Serra do Botucaraí não informavam em seus editais o local e a periodicidade da entrega. 
Figura 5: Conformidade dos editais de chamada pública dos 28 municípios pesquisados

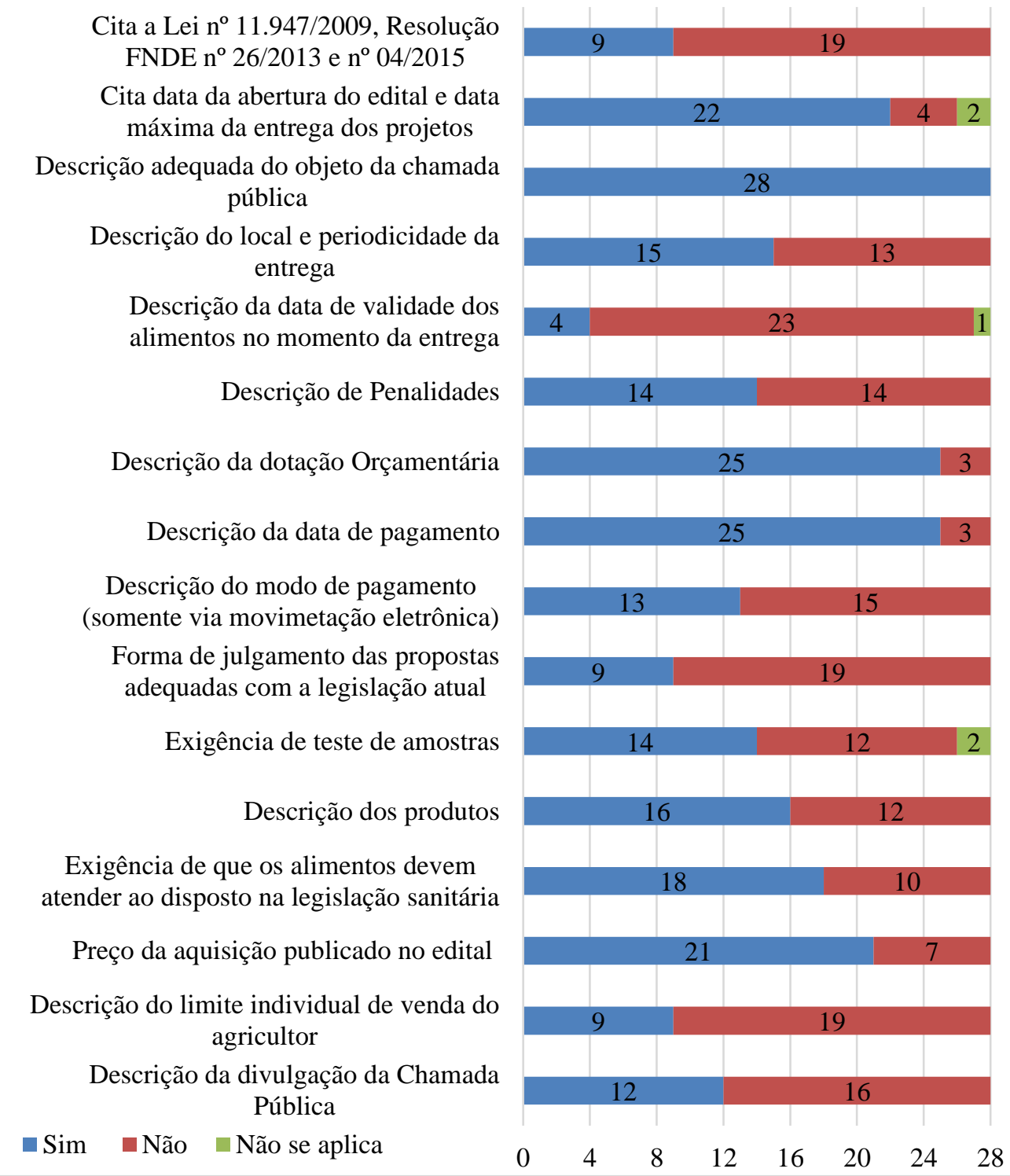

Fonte: Elaborado pelos autores com base nos dados de pesquisa (2019).

A maior parte dos editais (23) não informou o prazo de validade dos gêneros a serem entregues, no entanto esse ponto deve ser relativizado ao ser considerado que grande parte dos gêneros provenientes da agricultura familiar são produtos in natura. Tal como recomendado pela Resolução 04/2015, metade das EEx informavam penalidades aos fornecedores, caso houvessem desistência e/ou não entrega dos produtos. De igual maneira, 25 municípios citavam em seus editais a dotação orçamentária do recurso investido em alimentação escolar, além de descreverem a data de pagamento dos gêneros. Contudo, sobre os pagamentos, a maior parte dos municípios não explicitou no edital a forma de realização dos mesmos, o que, como especificado em lei, deve ser feito apenas via movimentação eletrônica (BRASIL, 2015; FNDE, 2016).

A forma de julgamento das propostas também se destaca como um ponto negativo na maior parte dos municípios. Como pode ser visto pela figura 5 , apenas nove municípios julgam as propostas de maneira adequada. Tal erro tanto descaracteriza o processo de chamada pública, como também prejudica os fornecedores locais, agricultores tradicionais, orgânicos agroecológicos e aqueles ligados a cooperativas ou associações. Regionalmente é nas Missões que há maior frequência de erros no julgamento das propostas, de modo que apenas um município contava com um modo de seleção adequado. Outro ponto de destaque é a exigência de testes de amostra, que foram descritos em 14 editais, enquanto a necessidade de atendimento à legislação sanitária foi descrita em 18 documentos. Verificou-se ainda que, em 12 editais de chamada pública, não havia uma descrição adequada dos produtos a serem comprados. Sobre esse aspecto, em Goiás, um dos entraves para a operacionalização do PNAE, na ótica dos agricultores, tem relação direta com a inadequada 
descrição dos produtos demandados pelas entidades executas. (BARBOSA et al., 2018). A descrição é importante pois ela possibilita uma maior caracterização e especificação dos produtos a serem adquiridos por meio do detalhamento das informações sobre o mesmo. Reforça-se que essa elucidação evita, de forma direta, o fornecimento de produtos inadequados ou que não atendam às exigências descritas em edital.

Sete municípios, distribuídos pelas quatro regiões, não fizeram constar em seus editais o preço de aquisição dos alimentos, desqualificando e descaracterizando a compra por chamada pública. Essa informação é de fundamental importância, uma vez que a sua ausência impede o agricultor de avaliar as vantagens financeiras de comercializar com o PNAE, de modo que, para Triches e Silvestri (2018), a não publicização do preço a ser pago pelos gêneros reduz o interesse dos agricultores em participar do PNAE. Analisando 114 chamadas públicas de 52 municípios do Rio Grande do Sul, Ferigollo et al. (2017) apontam que 40\% dos editais não continham o preço dos produtos. A descrição do limite individual de comercialização de 20 mil reais, por DAP, ao ano, apenas foi apresentado em nove editais de chamada pública e em 16 municípios não houve a descrição do local de divulgação da chamada pública no documento. Dado o caráter do PNAE, a divulgação da chamada pública é considerada fundamental, para que se possa ter um processo transparente e justo de compra da agricultura familiar.

Por último, relativamente ao quarto eixo de perguntas abrangidas pelos questionários, quando perguntado sobre a importância da agricultura familiar para o desenvolvimento do município, grande parte dos entrevistados apontou que a mesma é muito importante $(83,13 \%)$, ou importante $(12,05 \%)$. Regionalmente, foi nas Missões que a maior importância foi atribuída $(95,65 \%)$, enquanto os menores percentuais ocorreram nas regiões Sul e Alto da Serra (79\%). Já sobre a importância do PNAE para o fortalecimento da agricultura familiar nos municípios estudados, mais de $80 \%$ dos entrevistados das regióes Sul, Missões e Médio Alto Uruguai, atribuíram muita importância, enquanto, na região Alto da Serra do Botucaraí, os que atribuíram muita importância chegou a $66 \%$ dos entrevistados. Na tabela 3, são apresentadas a opinião sobre o grau de interesse dos agricultores em comercializar para o PNAE e o percentual de compras para o PNAE passível de ser atingido pela EEx.

Tabela 3: Opinião sobre o nível de interesse dos agricultores locais, e percentual de compra potencialmente atingível

\begin{tabular}{|c|c|c|c|c|}
\hline \multirow[b]{2}{*}{ Respondentes } & \multicolumn{4}{|c|}{ Nível de interesse dos agricultores locais em vender para o PNAE } \\
\hline & \multicolumn{2}{|c|}{ Nenhum interesse Baixo interesse } & \multirow{2}{*}{$\begin{array}{r}\text { Interesse } \\
42,86 \%\end{array}$} & \multirow{2}{*}{$\begin{array}{c}\text { Alto interesse } \\
28,57 \%\end{array}$} \\
\hline Nutricionistas ${ }^{1}$ & $10,71 \%$ & $17,86 \%$ & & \\
\hline Gestores $^{2}$ & $7,14 \%$ & $25,00 \%$ & $35,71 \%$ & $32,14 \%$ \\
\hline Emater $^{3}$ & $0,00 \%$ & $18,52 \%$ & $44,44 \%$ & $37,04 \%$ \\
\hline $\operatorname{Todos}^{4}$ & $6,02 \%$ & $20,48 \%$ & $40,96 \%$ & $32,53 \%$ \\
\hline Região Sul $^{4}$ & $4,76 \%$ & $38,10 \%$ & $19,05 \%$ & $38,10 \%$ \\
\hline Região Médio Alto Uruguai ${ }^{4}$ & $0,00 \%$ & $11,11 \%$ & $72,22 \%$ & $16,67 \%$ \\
\hline Região Alto da Serra ${ }^{4}$ & $9,52 \%$ & $28,57 \%$ & $33,33 \%$ & $28,57 \%$ \\
\hline \multirow[t]{2}{*}{ Região Missões $^{4}$} & $8,70 \%$ & $4,35 \%$ & $43,48 \%$ & $43,48 \%$ \\
\hline & \multicolumn{4}{|c|}{ Percentual de compra de gêneros da AF para o PNAE potencialmente atingível } \\
\hline Respondentes & $1 \%$ a $30 \%$ & $31 \%$ a $50 \%$ & $51 \%$ a $75 \%$ & Mais que $75 \%$ \\
\hline Nutricionistas 1 & $21,43 \%$ & $67,86 \%$ & $10,71 \%$ & $0,00 \%$ \\
\hline Gestores $^{2}$ & $32,14 \%$ & $50,00 \%$ & $14,29 \%$ & $3,57 \%$ \\
\hline Emater $^{3}$ & $11,11 \%$ & $51,85 \%$ & $22,22 \%$ & $14,81 \%$ \\
\hline Todos ${ }^{4}$ & $21,69 \%$ & $56,63 \%$ & $15,66 \%$ & $6,02 \%$ \\
\hline Região Sul $^{4}$ & $19,05 \%$ & $52,38 \%$ & $14,29 \%$ & $14,29 \%$ \\
\hline Região Médio Alto Urugua ${ }^{4}$ & $38,89 \%$ & $55,56 \%$ & $5,56 \%$ & $0,00 \%$ \\
\hline Região Alto da Serra ${ }^{4}$ & $23,81 \%$ & $47,62 \%$ & $23,81 \%$ & $4,76 \%$ \\
\hline Região Missões ${ }^{4}$ & $8,70 \%$ & $69,57 \%$ & $17,39 \%$ & $4,35 \%$ \\
\hline
\end{tabular}

Fonte: Elaborado pelos autores com base nos dados de pesquisa (2019) ${ }^{1}$ Questionário Nutricionista ${ }^{2}$ Questionário Gestores ${ }^{3}$ Questionário Emater ${ }^{4}$ Todos os três questionários

Chama a atenção o fato de que são altos os percentuais atribuídos a "nenhum interesse" ou "baixo interesse" dos agricultores para comercialização no PNAE nas regiões Sul e Alto da Serra do Botucaraí, os quais somam percentuais próximos a $40 \%$ das respostas. De todo modo, menos para a 
região Sul, tal desinteresse pode ter relação tanto com o menor percentual de estabelecimentos de agricultura familiar quanto também pelo baixo índice de diversificação da agropecuária. Quanto à opinião sobre o potencial de compra potencialmente atingível, grande parte dos entrevistados, em todas as regióes, aponta ser possível ultrapassar a compra mínima da agricultura familiar, sendo que os respondentes da região Sul e Missões são os maiores entusiastas para o alcance de percentuais que ultrapassem o limite mínimo. Porém, é curioso o fato de que na região médio Alto Uruguai quase $40 \%$ dos entrevistados opinaram que o percentual atingível está abaixo do limite mínimo de compra estipulado em lei, porém tal opinião pode ter relação com a não disposição de serviço de inspeção sanitária para produtos de maior valor agregado. Ao considerar que o PNAE é um programa complexo, que apresenta diversas especificidades e envolve diversos atores (TRICHES; KILIAN, 2016), a opinião e a motivação dos mesmos é de fundamental importância na execução dessa política pública.

\section{Considerações finais}

Este estudo teve como preocupação caracterizar e analisar as dificuldades de operacionalização da compra da agricultura familiar para o PNAE em municípios com percentual de aquisição inferior a 30\% no estado do Rio Grande do Sul. Com base nos dados coletados e analisados, surgem algumas reflexões. Embora deva ser ratificado que as causas das dificuldades de operacionalização não se restringem a uma ou outra variável, é válido o esforço de apresentação dos principais problemas identificados, bem como as suas inter-relações. Verifica-se, de uma maneira geral, que é comum nos municípios analisados a falta de profissionais compondo o quadro técnico no setor de alimentação escolar, sendo que tal déficit de profissionais tende a fragilizar, ou ao menos dificultar, a possibilidade de mapeamento dos produtos da agricultura familiar local, bem como o desenvolvimento de articulações com os atores envolvidos no PNAE. Em conjunto, essas fragilidades parecem justificar, em alguma medida, o índice relativamente alto de casos de frustração de compra de gêneros contemplados nos editais de chamada pública, o que também acaba por diminuir a compra planejada, pelas Entidades Executoras, da agricultura familiar.

Em mesma medida, é plausível argumentar que o desconhecimento e não aplicação, por parte das Entidades Executoras, de pontos fundamentas da legislação que rege o PNAE - principalmente aquelas destacadas na Resolução 04/2015 - como modo de definição de preços para chamada pública, publicização dos preços no edital, descrição adequada da periodicidade e dos locais de entrega, são aspectos que contribuem para diminuir o interesse dos agricultores em comercializar para o PNAE, causando, ao fim e ao cabo, dificuldades para a efetuação da compra mínima. De igual forma, a aparente falha de publicização do próprio edital de chamada pública e o equívoco cometido por alguns municípios na forma de julgar as propostas também tendem a colaborar com o aumento da dificuldade de se encontrar agricultores interessados em atender esse mercado institucional. Assim, pode-se dizer que tanto a insuficiência de recursos humanos para operacionalização da política, como o desconhecimento de pontos importantes da legislação são aspectos importantes para as dificuldades de compra da agricultura familiar nos municípios analisados.

Em termos regionais, na região Sul, estão localizados os municípios com maiores dificuldades em alcançar a compra mínima estipulada, bem como aqueles com maior déficit de profissionais de nutrição. Os editais de chamada pública da região Alto da Serra do Botucaraí e Missões apresentam problemas graves. Por sua vez, a região Médio Alto Uruguai é aquela que parece mais ter dificuldade com a falta de serviço de inspeção sanitária para produtos processados. Enfim, cabe destacar que, apesar dos avanços que o PNAE teve ao longo dos anos em temos legais, sua operacionalização no nível das Entidades Executoras ainda precisa de aperfeiçoamentos. Contudo, mesmo em meio às dificuldades, a opinião hegemônica dos atores envolvidos nessa pesquisa é que o PNAE é uma política pública de fundamental importância, a qual contribui para o fortalecimento da agricultura familiar e para o desenvolvimento local e que estratégias precisam ser pensadas e desenvolvidas para melhorar a qualidade dos processos que envolvem a compra institucional, especialmente no que tange à agricultura familiar, sendo esse um avanço não só econômico mas social e voltado à saúde no ambiente escolar.

\section{Referências}


BACCARIN, J. G. et al. Alimentação escolar e agricultura familiar: alcance e dificuldades para implantação do artigo 14 da Lei 11947/2009 no Estado de São Paulo. 49., Belo Horionte, MG. Anais...Belo Horizonte: SOBER, 2011

BARBOSA, M. I. D. C. et al. From family farmer to school : challenges and potentialities in the purchase from family farming for the school food program in municipalities of Goiás. 3., Porto Alegre, RS. Anais...Porto Alegre: AgUrb, 2018

BRASIL. Lei n 11.947/2009. 2009, p. 1-8.

BRASIL. Resolução CD/FNDEN 26, de 17 de junho de 2013. 2013, p. 1-44.

BRASIL. Resolução No 4, de 2 de abril de 2015. 2015, p. 22-23.

BRATKOWSKI, G. R. et al. Execution of the National School Feeding Program in the Municipalities of Rio Grande do Sul : An account of the experience and advances. 3., Porto Alegre, RS. Anais...Porto Alegre: AgUrb, 2018

CFN. Resolução no 465, de 23 de agosto de 2010. 2010, p. 118.

ESTEVAM, D. O.; SALVARO, G. I. J.; SANTOS, V. J. D. Os desafios da inserção formal de produtos da agricultura familiar no mercado. Redes, v. 23, n. 1, p. 262-281, 2018.

FEE. FEE Dados. Disponível em: < http://feedados.fee.tche.br/feedados/>. Acesso em: 5 maio 2018.

FERIGOLLO, D. et al. Aquisição de produtos da Agricultura Familiar para a Alimentação Escolar em municípios do Rio Grande do Sul. Revista de Saúde Publica, v. 51, n. 6, p. 1-10, 2017.

FNDE. Aquisição de produtos da agricultura familiar para a alimentação escolar $2^{\mathrm{a}}$ edição. Brasília: [s.n.].

FNDE. Dados da Agricultura Familair. Disponível em: <https://www.fnde.gov.br/programas/pnae/pnae-consultas/pnae-dados-da-agricultura-familiar > . Acesso em: 10 maio 2018.

FORNAZIER, A.; BELIK, W. The connection between family farming and school feeding in a major Brazilian city. 2., Roma. Anais...Rome: AgUrb, 2015

FRANCK, T. et al. Potencial de compras públicas como mercado para a agricultura familiar - uma análise do PNAE entre 2011 - 2014. 54., Maceio, AL. Anais...Maceio: SOBER, 2016

GRISA, C.; SCHNEIDER, S. Três Gerações de Políticas Públicas para a Agricultura Familiar e Formas de Interação entre Sociedade e Estado no Brasil. Revista de Soiologia Rural, v. 52, n. 1, p. S125-S146, 2015.

GUILHOTO, J. J. M. et al. A importância do agronegócio familiar no Brasil. Revista de Economia Rural, v. 44, n. 3, p. 355-382, 2006.

IBGE. Censo Agropecuário 2006. 2006

MALINA, M. M. Chamada Pública: instrumento legal de compra da agricultura familiar para a alimentação escolar. In: CORÁ, M. A. J.; BELIK, W. (Org.). Projeto NUTRE-SP: análise da inclusão da agricultura familiar na alimentação escolar no estado de São Paulo. São Paulo: Instituto Via Pública, 2012. p. 15-28.

MALUF, R. S. Alimentação, escola e agricultura familiar. Rio de Janeiro: Editora da UFRJ.2009 
MIGUEL, L. DE A. Dinâmica e Diferenciação de Sistemas Agrários. 2. ed. Porto Alegre: Editora da UFRGS, 2018.

SILVA, T. M. DA; ROCHETT, F. C.; COELHO DE SOUZA, G. Desenvolvimento Territorial e o Progrma Nacional de Alimentação Escolar nos Territórios Rurais Litoral e Campos de Cima da Serra no Rio Grande do Sul. Revista Brasileira de Gestão e Desenvolvimento Regonal, v. 14, n. 1, p. 61$85,2018$.

SILVA NETO, B.; OLIVEIRA, A. DE. Agricultura familiar, desenvolvimento rural e formação dos municípios do Estado do Rio Grande do Sul. Estudos sociedade e agricultura, v. 16, n. 1, p. 83-108, 2008.

SOUSA, D. N. DE et al. Progrmas Governamentais de Aquisição de Alimentos da Agricultura Familiar no Estado do Tocantins. Revista Brasileira de Gestão e Desenvolvimento Regonal, v. 14, n. 5, p. 253-264, 2018.

SWENSSON, L. F. J. The role of public procurement regulatory framework for the implementation of public food procurement initiatives targeting family farmers. 3., Porto Alegre, RS. Anais...Porto Alegre: AgUrb, 2018.

TRICHES, R. M. O Programa de Alimentação Escolar nutrindo o desenvol- vimento: ideias e relações inovadoras. In: SCHNEIDER, S. et al. (Eds.). . Sementes e brotos da transição: inovação, poder e desenvolvimento em áreas rurais do Brasil. 1. ed. Porto Alegre: Editora da UFRGS, 2014. p. 115139.

TRICHES, R. M. Repensando o mercado da alimentação escolar: novas institucionalidades para o desenvolvimento rural. In: GRISA, C.; SCHNEIDER, S. (Org.). Políticas Públicas de Desenvolvimento Rural no Brasil. 1. ed. Porto Alegre: Editora da UFRGS, 2015. p. 623.

TRICHES, R. M.; KILIAN, L. Papel dos Atores Sociais na Aquisição de Produtos da Agricultura Familiar para Alimentção Escolar em Municípios Paranaenses. Redes, v. 21, n. 3, p. 159-179, 2016.

TRICHES, R. M.; SCHNEIDER, S. Reconstruindo o "elo perdido": a reconexão da produção e do consumo de alimentos através do Programa De Alimentação Escolar no município de Dois Irmãos (RS). Segurança Alimentar e Nutricional, v. 17, n. 1, p. 1, 2010.

TRICHES, R. M.; SILVESTRI, F. Adequação das Chamadas Públicas para Aquisição de Produtos da Agricultura Familiar para a Alimentação Escolar. Desenvolvimento em Questão, v. 16, n. 44, p. 26, 2018.

VILLAR, B. S. et al. Situação dos municípios do estado de São Paulo com relação à compra direta de produtos da agricultura familiar para o Programa Nacional de Alimentação Escolar (PNAE). Revista Brasileira de Epidemiologia, v. 16, n. 1, p. 223-226, 2013.

WAQUIL, P. D.; FILIPPI, E. E. Desigualdades regionais e desempenho diferenciado dos municípios do Rio Grande do Sul : uma análise a partir de elementos rurais. 50., 2008, Rio Branco, AC. Anais...Rio Branco: SOBER, 2008 